\title{
Effects of CPAP on "vascular" risk factors in patients with obstructive sleep apnea and arterial hypertension
}

This article was published in the following Dove Press journal:

Vascular Health and Risk Management

9 May 2013

Number of times this article has been viewed

\section{AY Litvin' \\ ZN Sukmarova' \\ EM Elfimova' \\ AV Aksenova' \\ PV Galitsin' \\ AN Rogoza ${ }^{2}$ \\ IE Chazova'}

'Department of Systemic Hypertension, ${ }^{2}$ Department of New Methods of Diagnostics, Russian Cardiology Research and Production Complex, Ministry of Health, Moscow, Russian Federation
Correspondence: AY Litvin Russian Cardiology Research and Production Complex, Ministry of Health, 3rd Cherepkovskay Str 15 A,

Moscow 121552, Russian Federation

$\mathrm{Tel}+74954146834$

Fax +74954I46834

Email alelitvin@yandex.ru
Background: The aim of this study was to assess the effects of continuous positive airway pressure (CPAP) on arterial stiffness, central blood pressure, and reflected pulse wave characteristics in patients with severe obstructive sleep apnea (OSA) and stage 2-3 arterial hypertension.

Methods: Forty-four patients with hypertension and severe OSA (apnea/hypopnea index > 30) received stepped dose titration of antihypertensive treatment, consisting of valsartan $160 \mathrm{mg}+$ amlodipine 5-10 mg + hydrochlorothiazide $25 \mathrm{mg}$. CPAP therapy was added after 3 weeks of continuous antihypertensive treatment with BP $<140 / 90 \mathrm{mmHg}$ or after adjusting triple treatment in patients with resistant arterial hypertension. The patients were randomized to effective CPAP (4-15 $\mathrm{mm} \mathrm{H}_{2} \mathrm{O}$ ) or placebo CPAP (pressure $4 \mathrm{~mm} \mathrm{H}_{2} \mathrm{O}$ ) for three weeks, then crossed over to the alternative treatment in a single-blind manner. Office blood pressure (BP), ambulatory BP monitoring, ambulatory arterial stiffness index (AASI), aortic BP, carotid-femoral pulse wave velocity (cfPWV), and systolic wave augmentation index were measured using a Sphygmocor ${ }^{\circledR}$ device at baseline, after antihypertensive treatment, placebo CPAP, and effective CPAP.

Results: Baseline cfPWV was above the normal range in $94 \%$ of patients. After reaching target BP, the cfPWV decreased by $1.9 \pm 1.0 \mathrm{msec}(P=0.007)$. Effective CPAP achieved a further cfPWV reduction of $0.7 \mathrm{msec}(P=0.03)$. Increased arterial stiffness (pulse wave velocity $>12 \mathrm{msec}$ ) persisted in $35 \%$ of patients on antihypertensive treatment and effective CPAP, in $56 \%$ of patients on antihypertensive treatment alone, and in 53\% of patients on placebo CPAP. Only the combination of antihypertensive treatment with effective CPAP achieved a significant reduction in augmentation index and AASI, along with a further reduction in aortic and brachial BP.

Conclusion: Effective CPAP for 3 weeks resulted in a significant additional decrease in office BP, ambulatory BP monitoring, central BP, and augmentation index, together with an improvement in arterial stiffness parameters, ie, cfPWV and AASI, in a group of hypertensive patients with OSA.

Keywords: antihypertensive therapy, hypertension, obstructive sleep apnea, continuous positive airway pressure, blood pressure, arterial stiffness, pulse wave velocity

\section{Introduction}

Obstructive sleep apnea (OSA) is a highly prevalent condition. According to population studies, about $24 \%$ of men aged 30-60 years and $9 \%$ of women are estimated to have OSA. ${ }^{1}$ The close association between OSA, overweight/obesity, and cardiovascular morbidity and mortality is a major health problem. ${ }^{2,3}$ Several studies have indicated a causal relationship between OSA and hypertension, diabetes mellitus, and cardiovascular disease. ${ }^{2}$ In fact, the relative risk of all-cause mortality in patients with severe OSA has been reported to be 1.5 times higher than in patients without OSA. 
Severe OSA significantly increases the risk of fatal and nonfatal cardiovascular events, ${ }^{4,5}$ and the apnea/hypopnea index has been identified to be an independent predictor of cardiovascular events, particularly in middle-aged individuals with OSA. ${ }^{6}$

Interventional studies revealed substantial improvement in symptoms associated with OSA, ie, daytime sleepiness, snoring, morning headaches, and reduction in BP, in patients receiving continuous positive airway pressure (CPAP) therapy. Moreover, the benefits of effective CPAP on reduction of cardiovascular risk and fatal and nonfatal cardiovascular events have been established in multiple large trials..$^{2,5,7,8}$

The pathogenesis of cardiovascular disease in patients with OSA is not completely elucidated. Various mechanisms may be involved, ${ }^{9}$ including intermittent hypoxia, which has been described as the main trigger for cardiovascular and metabolic changes. ${ }^{3}$ Sympathetic activation, vascular endothelial dysfunction, and metabolic dysregulation, together with oxidative stress and inflammation, ${ }^{10}$ may contribute to increased blood pressure (BP) with a pathological circadian profile and variability. ${ }^{2}$ These mechanisms have been considered to explain the beneficial outcomes of CPAP. In this regard, abnormalities in both the small and large arteries are an attractive target. In fact, studies have reported that patients with OSA show vasoreactive dysfunction, vascular remodeling, ${ }^{11}$ and accelerated progression of atherosclerosis. ${ }^{12}$ Considering arterial stiffness as a new marker of cardiovascular risk, ${ }^{13}$ it has been recently reported ${ }^{14,15}$ as being increased in patients with OSA. ${ }^{16,17}$ Moreover, recent meta-analyses of CPAP in patients with OSA have shown significant improvements in all parameters of arterial stiffness. ${ }^{13}$ The objective of the present study was to assess the effects of CPAP on arterial stiffness, central BP, and reflected pulse wave characteristics in patients with severe OSA and grade 2-3 arterial hypertension.

\section{Materials and methods}

From May 2007 to August 2009, 112 patients with suspected OSA and grade 2-3 arterial hypertension were identified at the Russian Scientific Cardiology Research and Production Center. All these patients underwent full polysomnography and a trial of CPAP. Fifty-five percent were excluded from participation in this study due to comorbidities, including diabetes, persistent atrial fibrillation, severe ventricular rhythm disorders, an implanted pacemaker, chronic use of hypnotics, fluctuations in body mass, or being intolerant to CPAP. The study was approved by the local ethics committee at the Russian Scientific Cardiology Research and Production Center, and is registered at ClinicalTrials.gov (NCT00801671). Fifty patients were enrolled.

\section{Study protocol}

All patients underwent standard overnight polysomnography (Embla, Reykjavik, Iceland) as previously described ${ }^{18}$ (Figure 1). Only patients with severe OSA (apnea-hypopnea index $>30$ events per hour) were included. The patients initially underwent Somnobalance-e, (Weinmann, Hamburg, Germany) for CPAP. Compliance with CPAP was determined from time-pressure data downloaded from the CPAP device. Arterial hypertension was diagnosed according to current guidelines published by the European Society of Hypertension. ${ }^{19}$ BP measurements were determined using a conventional mercury sphygmomanometer. ${ }^{20}$ Resistant hypertension was diagnosed when lifestyle measures and treatment with at least three drugs (including a diuretic) at adequate doses had failed to lower systolic and diastolic BP to target. $^{20}$

Any previous antihypertensive treatment was discontinued for at least five half-lives (6-10 days). During this washout period, the patients were treated with a short-acting antihypertensive treatment (captopril $25 \mathrm{mg}$ as needed) and were instructed to measure their BP at home at least four times a day. The patients then received stepped dose titration of antihypertensive treatment every three weeks if BP was uncontrolled $(<140 / 90 \mathrm{mmHg})$. The first step was valsartan $160 \mathrm{mg}+$ amlodipine $5 \mathrm{mg}$, the second step was valsartan $160 \mathrm{mg}+$ amlodipine $10 \mathrm{mg}$, and the third step was valsartan $160 \mathrm{mg}$ + amlodipine $10 \mathrm{mg}$ + hydrochlorothiazide $25 \mathrm{mg}$. CPAP was added after three weeks of continuous antihypertensive treatment with BP $<140 / 90 \mathrm{mmHg}$, or after adjusting triple therapy over three weeks in patients with refractory arterial hypertension. Patients were randomized to receive either effective CPAP in automatic mode (pressure 4-15 $\mathrm{mm} \mathrm{H}_{2} \mathrm{O}$ ) or placebo CPAP (pressure $4 \mathrm{~mm} \mathrm{H}_{2} \mathrm{O}$ ). After three weeks, the patients were crossed over to the alternative ventilation regimen in a single-blind manner.

The carotid-femoral pulse wave velocity (cfPWV), central BP, and systolic wave augmentation index were measured using a Sphygmocor ${ }^{\circledR}$ device (AtCor Medical, Sydney, Australia). The direct carotid-femoral distance was measured for calculation of cfPWV, ${ }^{21}$ and 24-hour ambulatory BP monitoring was performed using the BPLab device (Peter Telegin Ltd, Nizhny Novgorod, Russia) every 20 minutes during the day and every 30 minutes at night. Ambulatory arterial stiffness index (AASI) was calculated using a software module based on the 24-hour 


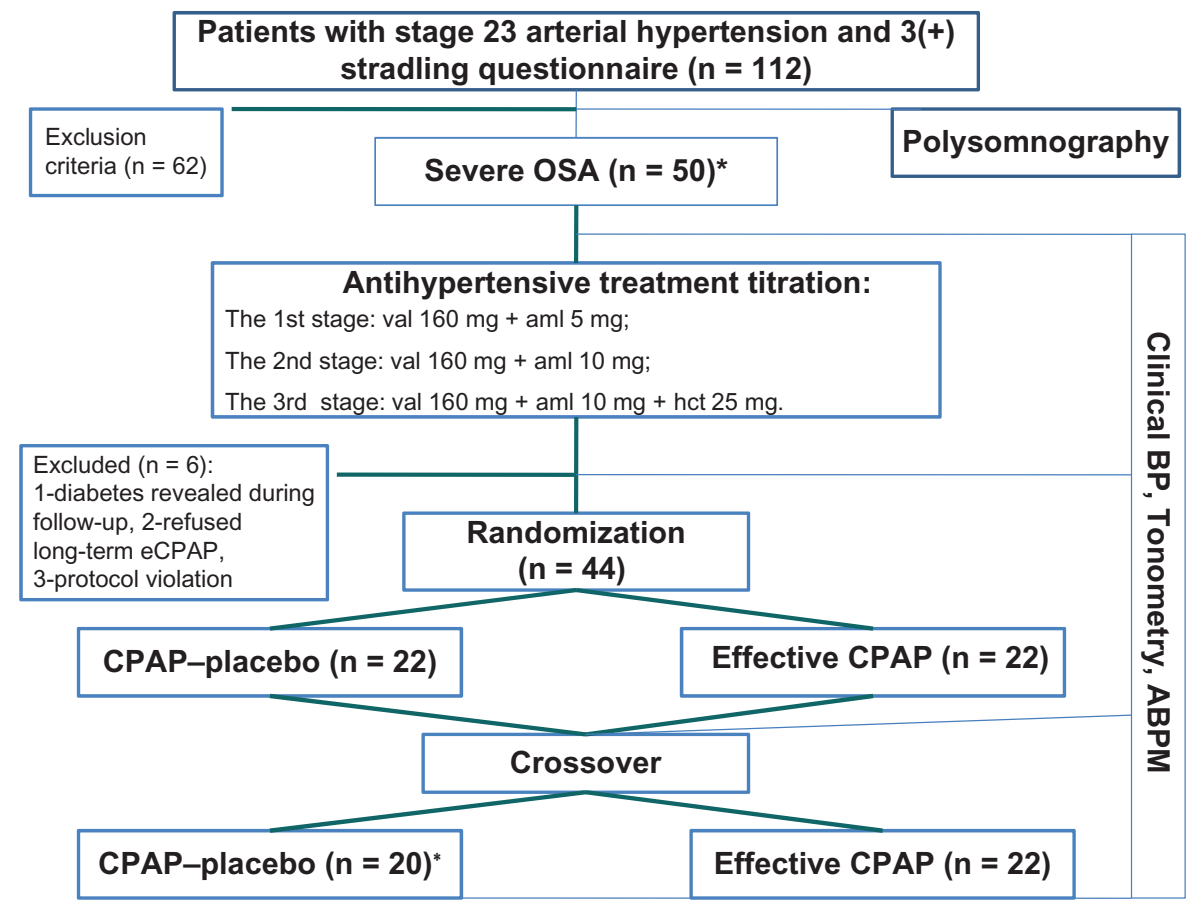

Figure I Study design.

Note: Of the remaining 44 patients, two subjects refused PCPAP because of complaints of "shortness of breath" and fail to fall asleep, This was taken into account in the statistical analysis.

Abbreviations: ABPM, ambulatory blood pressure monitoring; BP, blood pressure; val, valsartan; aml, amlodipine; HCT, hydrochlorothiazide; CPAP, continuous positive airways pressure; eCPAP, effective CPAP; PCPAP, placebo CPAP; OSA, obstructive sleep apnea.

BP monitoring data, and was considered to be increased if it exceeded 0.5.22

\section{Statistical analysis}

The data analysis was performed using InStat 3.0 software (GraphPad, San Diego, CA, USA). The data are presented as the mean \pm standard deviation; if non-normally distributed, they are shown as the median (5-95 percentile). A two-tailed Mann-Whitney $U$ test was used for parameters that showed changes during treatment. The correlation between variables was determined by univariate regression analysis. An alpha level of $5 \%$ was considered to be statistically significant.

\section{Results}

The mean observation period was $13.2 \pm 1.5$ weeks for the 34 men and ten women who completed the study. All patients were Caucasian and obese ( $89 \%$ had a body mass index $>30)$. Two-thirds $(\mathrm{n}=31)$ were diagnosed with stage 2 arterial hypertension (Table 1).

\section{Blood pressure}

Forty-four participants had stage 2-3 arterial hypertension and severe OSA, of whom ten received valsartan $160 \mathrm{mg}$ + amlodipine $5 \mathrm{mg}$, six received valsartan $160 \mathrm{mg}+$ amlodipine, and 28 received valsartan $160 \mathrm{mg}+$ amlodipine $10 \mathrm{mg}+$ hydrochlorothiazide $25 \mathrm{mg}$. Twenty-five patients (57\%) who received valsartan $160 \mathrm{mg}+$ amlodipine $10 \mathrm{mg}+$ hydrochlorothiazide $25 \mathrm{mg}$ did not achieve a target office BP pressure $<140 / 90 \mathrm{mmHg}$, so were considered to be refractory to treatment.

On antihypertensive therapy, brachial systolic BP decreased by $25.4 \pm 12.1 \mathrm{mmHg}$ and brachial diastolic BP by $11.6 \pm 2.0 \mathrm{mmHg}$. Changes in central systolic and diastolic BP were $26.0 \pm 13.7 \mathrm{mmHg}$ and $11.0 \pm 1.6 \mathrm{mmHg}$,

Table I Main characteristics of the population

\begin{tabular}{ll}
\hline Gender (M/F) & $34 / 10$ \\
Age (years) & $55.5 \pm 9.6$ \\
Body mass index $\left(\mathrm{kg} / \mathrm{m}^{2}\right)$ & $37.7 \pm 7.8$ \\
Apnea-hypopnea index (obstructive events per hour) & $63.4 \pm 26.3$ \\
Mean duration of arterial hypertension (years) & $15.7 \pm 7.3$ \\
Previous antihypertensive treatment ( $\mathrm{n})$ & 27 \\
Mean blood pressure (mmHg) & $119.9 \pm 11.3$ \\
Smoking status: current/former (n/\%) & $3(10)$ \\
Glucose abnormalities (n/\%) & $29(66)$ \\
Very high and high risk according to ESH guideline (n, \%) & $31(73)$ \\
SCORE (\%) & $9.4 \pm 5.1$ \\
\hline
\end{tabular}

Note: Mean \pm standard deviation.

Abbreviations: ESH, European Society of Hypertension; SCORE, Systemic Coronary Risk Evaluation. 
respectively (Table 2). Aortic BP showed a somewhat greater decrease than brachial systolic BP $(-16.5 \% \pm 7.8 \%$ versus $-14.9 \% \pm 7.8 \%, P=0.047)$ on antihypertensive therapy.

Adding effective CPAP to medical antihypertensive therapy resulted in an additional $\mathrm{BP}$ reduction, in central systolic BP $(-6.7 \pm 1.1 \mathrm{mmHg}, P=0.006)$, diastolic BP $(-4.6 \pm 0.5 \mathrm{mmHg}, P=0.002$, Table 2$)$, brachial systolic BP $(-5.8 \pm 1.0 \mathrm{mmHg}, P=0.05)$ and diastolic BP $(-4.5 \pm 0.5 \mathrm{mmHg}, P=0.04)$. The difference in relative reduction of central $\mathrm{BP}$ and office brachial $\mathrm{BP}$ reached statistical significance only for the systolic component $(6.1 \% \pm 1.1 \%$ versus $4.3 \% \pm 1.1 \%, P<0.05)$

In comparison with placebo CPAP, switching patients to effective CPAP showed a respective decrease in both central and office brachial BP of $-4.4 \pm 0.4 \mathrm{mmHg}(P=0.4)$ and $-4.6 \pm 0.6 \mathrm{mmHg}(P=0.06)$. Diastolic changes were significant only for central BP $(-4.0 \pm 0.4 \mathrm{mmHg}, P=0.02)$ and not for office brachial BP $(-3.4 \pm 1.0 \mathrm{mmHg}, P=0.1)$.

On combined therapy (antihypertensive treatment + effective CPAP), the reduction in office brachial BP was $31.2 \pm 11.1 \mathrm{mmHg} / 15.9 \pm 9.3 \mathrm{mmHg}$ and in central BP was $32.7 \pm 4.0 \mathrm{mmHg} / 16.5 \pm 13.9 \mathrm{mmHg}$. Placebo CPAP was not associated with a significant decrease in BP. Ventilatory support per night was $5.1 \pm 1.6$ hours, and the respiratory disturbance index recorded by the CPAP device was $4.4 \pm 2.1$.

\section{Arterial stiffness}

The cfPWV was measured in 34 patients (with difficulty acquiring tonometry measurements in some obese patients, Table 2). In 32 patients (94\%), the results were above the normal age-adjusted range. Seventy-three percent of patients had a cfPWV above the upper limit of normal $(>12 \mathrm{~m} / \mathrm{sec}) .{ }^{20}$ After titration of antihypertensive treatment, when BP goal was achieved, cfPWV decreased by $1.9 \pm 1.0 \mathrm{~m} / \mathrm{sec}$ $(P=0.007)$. Placebo CPAP did not affect cfPWV, while effective CPAP achieved an additional reduction in cfPWV of $0.7 \mathrm{~m} / \mathrm{sec}(P=0.03)$. At the end of the study, increased arterial stiffness (cfPWV $>12 \mathrm{~m} / \mathrm{sec}$ ) persisted in $35 \%$ of patients receiving optimal antihypertensive treatment and effective CPAP, in $56 \%$ of patients on medical therapy alone, and in 53\% on placebo CPAP (Figure 2).

The AASI was increased in $61 \%$ of patients at baseline. After antihypertensive treatment, any changes in AASI did not reach statistical significance. AASI was reduced only after adding effective CPAP to medical therapy, with increased AASI persisting in $32 \%$ of patients (Figure 3). At baseline, the augmentation index was $25.6 \% \pm 11.1 \%$, and tended to decrease after antihypertensive treatment $(\Delta=4.0 \%, P=0.2)$. When medical therapy was combined with effective CPAP, the reduction in augmentation index increased up to $5.9 \%$ and reached statistical significance $(P=0.04)$.

\section{Overall cardiovascular risk}

Using the European Society of Hypertension guidelines for the management of arterial hypertension, ${ }^{20}$ a very high global cardiovascular risk was identified in 19 patients, high risk in 13 patients, and moderate risk in 12 patients. Using the Systemic Coronary Risk Evaluation chart, cardiovascular risk exceeded 4\% in 29 patients. Inclusion of an additional "vascular" factor, ie, arterial stiffness, as assessed by cfPWV, augmentation index, and AASI, substantially modified the overall cardiovascular risk, with four patients being switched from moderate risk to high risk.

\section{Discussion}

In the present study, addition of effective CPAP decreased arterial stiffness to a greater extent than medical therapy alone. Patients with severe OSA in this study were at high cardiovascular risk (9.4\%, using strict criteria) which is consistent with the published data citing a predicted Systemic Coronary Risk Evaluation risk of $13.9 \% .^{23}$

Table 2 Blood pressure values according to treatment regimen

\begin{tabular}{lcccc}
\hline Mean \pm SD & Baseline & AT & PCPAP & eCPAP \\
\hline Office systolic BP $(\mathrm{mmHg})$ & $166 \pm \mathrm{II}$ & $141 \pm 1 I^{*}$ & $140 \pm 9$ & $135 \pm 10^{\#}$ \\
Office diastolic BP $(\mathrm{mmHg})$ & $96 \pm \mathrm{II}$ & $85 \pm 8^{*}$ & $86 \pm 9$ & $80 \pm 8^{\#}$ \\
Central systolic BP $(\mathrm{mmHg})$ & $155 \pm \mathrm{II}$ & $129 \pm 1 I^{*}$ & $126 \pm 8$ & $122 \pm 10^{\#}$ \\
Central diastolic BP $(\mathrm{mmHg})$ & $97 \pm 13$ & $86 \pm 10^{*}$ & $85 \pm 10$ & $81 \pm 9^{\#}$ \\
PWV $(\mathrm{m} / \mathrm{sec})$ & $13.9 \pm 2.8$ & $12.0 \pm 2.5^{*}$ & $12.0 \pm 2.7$ & $1.3 \pm 2.7^{* * \#}$ \\
AASI & $0.55 \pm 0.17$ & $0.48 \pm 0.39$ & $0.54 \pm 0.28$ & $0.41 \pm 0.18^{*}$ \\
Alx75** & $25.6 \pm 11.1$ & $21.6 \pm 12.0$ & $21.7 \pm 15.1$ & $19.7 \pm 14.3^{*}$ \\
\hline
\end{tabular}

Notes: $* P<0.05$ versus baseline; ${ }^{*} P<0.05$ versus antihypertensive therapy; ${ }^{*}$ Alx values were normalized to a standard heart rate of 75 per minutes.

Abbreviations: AASI, ambulatory arterial stiffness index; Alx, augmentation index; AT, antihypertensive therapy; BP, blood pressure; CPAP, continuous positive airways pressure; eCPAP, effective CPAP; SD, standard deviation; PCPAP, placebo CPAP; PWV, pulse wave velocity. 


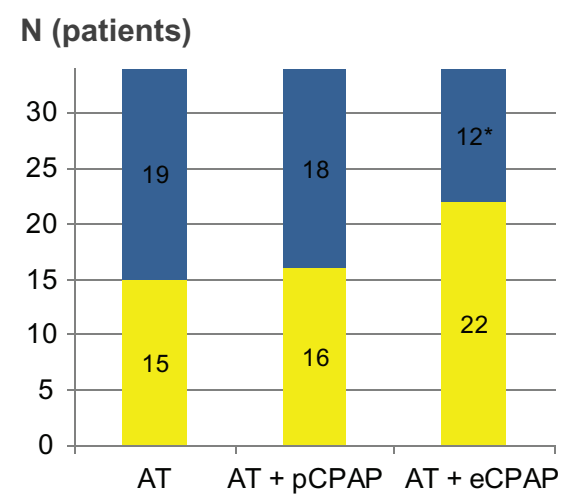

- Exceeded values PWV Goal values PWV

Figure 2 Pulse wave velocity recordings (normal $<12 \mathrm{~m} / \mathrm{sec}$ ). Note: $* P<0.05$ vs AT.

Abbreviations: AT, antihypertensive therapy; CPAP, continuous positive airways pressure; eCPAP, effective CPAP; pCPAP, placebo CPAP; PWV, pulse wave velocity.

In this study, integration of a further vascular factor resulted in a substantial amendment of global cardiovascular risk, with about one third of patients being switched from a moderate risk to a high risk category. This observation emphasizes the importance of assessing vascular factors when determining the risk profile of patients with severe OSA and arterial hypertension.

Seventy-three percent of our study population showed markedly high PWV values, which is in agreement with the data reported in the literature. ${ }^{13,23-25}$ In our study, patients treated with effective CPAP showed a further reduction in PWV of $0.7 \pm 0.6 \mathrm{~m} / \mathrm{sec}(P=0.03)$, with an almost 1.5 -fold increase in patients reaching target PWV (Figure 3). These changes are comparable with the mean PWV reduction of $0.7 \mathrm{~m} / \mathrm{sec}$ observed in patients on lipid-lowering therapy. ${ }^{14}$ It should be emphasized that, according to the literature,

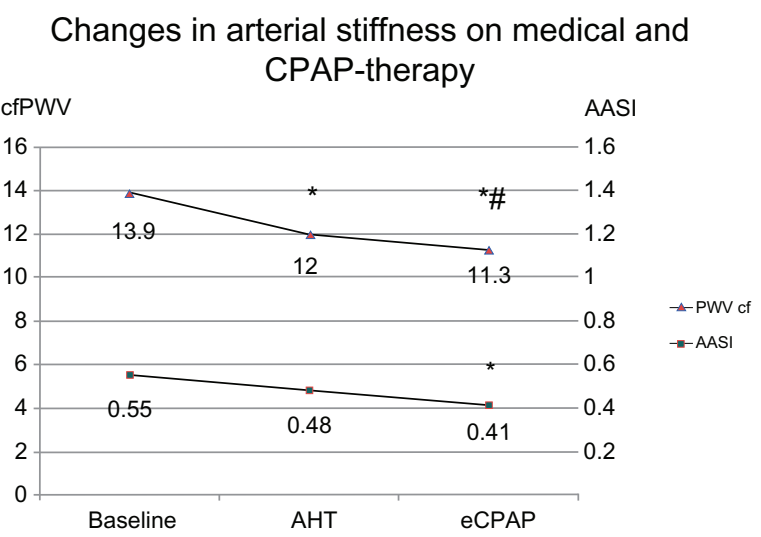

Figure 3 Changes in carotid-femoral PWV and AASI after antihypertensive therapy and CPAP therapy.

Notes: ${ }^{* P}>1.05$ vs baseline; ${ }^{\# P}>1.05$ vs AHT.

Abbreviations: AHT, antihypertensive therapy; eCPAP, effective continuous positive airways pressure; cfPWV, carotid-femoral pulse wave velocity; AASI, ambulatory arterial stiffness index. a decrease in PWV of $1.6 \mathrm{~m} / \mathrm{sec}$ is equivalent to functional "rejuvenation" of vessels for 15 years. ${ }^{26}$ Other parameters of arterial stiffness, such as AASI, showed less sensitivity than PWV, with significant changes seen only in patients on a combination of medical antihypertensive therapy and CPAP.

The initial augmentation index has been reported to be an independent risk factor for cardiovascular disease, and the augmentation index has been reported to be higher in patients with OSA than in controls. ${ }^{27}$ In our study, only addition of effective CPAP to antihypertensive therapy achieved a significant improvement in the augmentation index.

Several recent studies have reported that aortic pressure is a more precise predictor of target organ damage than conventional brachial BP. ${ }^{28}$ The central BP reduction observed in our study is in agreement with the results reported by Phillips et al after 2 months of CPAP $(-4.2 \mathrm{~mm} \mathrm{Hg}) .{ }^{29}$ It should be noted that this relatively minor central BP decrease may be significant in terms of prognosis, given the finding of the ASCOTCAFÉ study that an intergroup difference of $3.6 \mathrm{mmHg}$ in central BP decreased cardiovascular mortality by $24 \%$ and the risk of fatal and nonfatal stroke by $23 \% .{ }^{28}$ Moreover, the results of the CAFÉ study suggest that certain drugs have an "additional" effect on central BP, which may explain the benefits in terms of cardiovascular morbidity and mortality. The basis of this "additional" reduction in central BP seems to be related to an impact on arterial stiffness and the reflected wave, ie, if combination therapy using an angiotensin-converting enzyme inhibitor and a calcium antagonist is given. In our study, the duration of combination antihypertensive treatment was short, but seems to have been adequate to observe this "additional" effect on central BP. This "additional" decrease of central systolic BP was shown after effective CPAP was $6.1 \%$ $(P<0.05)$. Whereas decrease of office systolic blood pressure was just $4.3 \%(P<0.05)$. Therefore, our results suggest that the beneficial effect of CPAP in patients with OSA and arterial hypertension is related, at least in part, to an improvement in arterial stiffness and reflected wave parameters.

One should also take into consideration that a number of factors can potentially have a negative impact on the vasculature in patients with OSA. Nocturnal apneas initiate several pathophysiological mechanisms related to adrenergic activation, and are accompanied by chemoreflex-mediated increases in sympathetic activity in the peripheral blood vessels. Toward the end of an apneic episode, BP can reach levels as high as 240/130 $\mathrm{mmHg},{ }^{30}$ and the pattern of BP at night has specific features. ${ }^{2}$ Recurrent hypoxemic stress increases the release of vasoactive and trophic substances, including renin, noradrenaline, thromboxane A2, and 
endothelin, along with decreased production of vascular nitric oxide and high vasoconstriction reactivity. ${ }^{2}$ These abnormalities affect the stiffness of the arterial wall.

Another major mechanism leading to changes in the walls of the central arteries is protein glycation, which was very likely to have been present in the participants in this study, given that the majority of our patients had disordered glucose metabolism. Under chronic conditions, this leads to active vascular inflammation, and then to proliferation, consolidation of the intima, and changes in the media, resulting in stiffer arteries. The results seen in our study may be related to the effect of antihypertensive treatment on these parameters, with a further beneficial effect from CPAP.

There are several limitations to the present study. Although our findings show that effective CPAP for 3 weeks achieved a significant decrease in office BP, ambulatory BP monitoring, and central BP values, as well as improvement in the augmentation index and in arterial stiffness parameters, ie, cfPWV and AASI, it was a single-center study and is limited in power by its relatively small sample size and short duration. Although a number of potential confounding factors were addressed, the existence of other as yet unrecognized variables should not be overlooked.

Our study was limited to the use of applanation tonometry with the Sphygmocor and ambulatory BP monitoring. The blood pressure-independent impact of CPAP-therapy on arterial wall stiffness could be assessed with beta stiffness index and cardio-ankle vascular index (VaSera). ${ }^{31}$ However, this requires additional methods of investigation, such as ultrasonography and the VaSera vascular screening system.

\section{Conclusion}

In hypertensive patients with OSA, effective CPAP administered for 3 weeks achieved a significant additional decrease in office BP, ambulatory BP monitoring, and central BP values, together with an improvement in the augmentation index and arterial stiffness parameters, ie, cfPWV and AASI. Further studies in a larger number of patients are needed to confirm these observations.

\section{Disclosure}

The authors report no conflicts of interest in this work. Publication processing charges were funded by Novartis Pharma LLC, Moscow, Russia.

\section{References}

1. Young T, Palta M, Dempsey J, et al. The occurrence of sleep-disordered breathing among middle-aged adults. N Engl J Med. 1993;328: $1230-1235$.
2. Somers VK, White DP, Amin R, et al. Sleep apnea and cardiovascular disease: an American Heart Association/American College of Cardiology Foundation Scientific Statement from the American Heart Association Council for High Blood Pressure Research Professional Education Committee, Council on Clinical Cardiology, Stroke Council, and Council on Cardiovascular Nursing. J Am Coll Cardiol. 2008;52: 686-717.

3. McNicholas WT, Bonsignore MR; Management Committee of EU COST ACTION B26. Sleep apnea as an independent risk factor for cardiovascular disease: current evidence, basic mechanisms and research priorities. Eur Respir J. 2007;29:156-178.

4. Punjabi NM, Caffo BS, Goodwin JL, et al. Sleep-disordered breathing and mortality: a prospective cohort study. PLoS Med. 2009;6: e1000132.

5. Marin JM, Carrizo S, Vicente E, Agusti AG. Long-term cardiovascular outcomes in men with obstructive sleep apnea-hypopnoea with or without treatment with continuous positive airway pressure: an observational study. Lancet. 2005;365:1046-1053.

6. Pecker Y, Hedner J, Norum J, Kraiczi H, Carlson J. Increased incidence of cardiovascular disease in middle-aged men with obstructive sleep apnea: a 7 year follow-up. Am J Respir Crit Care Med. 2002;166: $159-165$.

7. Faccenda JF, Mackay TW, Boon NA, et al. Randomized placebocontrolled trial of continuous positive airway pressure on blood pressure in the sleep apnea-hypopnea syndrome. Am J Respir Crit Care Med. 2001;163:344-348.

8. Pepperell JCT, Ramdassingh-Dow S, Crosthwaite N, et al. Ambulatory blood pressure after therapeutic and subtherapeutic nasal continuous positive airway pressure for obstructive sleep apnoea: a randomized parallel trial. Lancet. 2001;359:204-210.

9. Ayers L, Ferry B, Craig S, Nicoll D, Stradling JR, Kohler M. Circulating cell-derived microparticles in patients with minimally symptomatic obstructive sleep apnoea. Eur Respir J. 2009;33:574-580.

10. Caples SM, Gami AS, Somers VK. Obstructive sleep apnea. Ann Intern Med. 2005;142:187-197.

11. Kraiczi H, Caidahl K, Samuelsson A, Peker Y, Hedner J. Impairment of vascular endothelial function and left ventricular filling: association with the severity of apnea-induced hypoxemia during sleep. Chest. 2001;119:1085-1091.

12. Lusis AJ. Atherosclerosis. Nature. 2000;407:233-241.

13. Drager LF, Bortolotto LA, Figueiredo AC, Silva BC, Krieger EM, Lorenzi-Filho G. Obstructive sleep apnea, hypertension and their interaction on arterial stiffness and heart remodeling. Chest. 2007;13: 1379-1386.

14. Mäki-Petäjä KM, Booth $\mathrm{AD}$, Hall FC, et al. Ezetimibe and simvastatin reduce inflammation, disease activity, and aortic stiffness and improve endothelial function in rheumatoid arthritis. JAm Coll Cardiol. 2007;50: $852-858$

15. Vlachantoni IT, Dikaiakou E, Antonopoulos CN, Stefanadis C, Daskalopoulou SS, Petridou ET. Effects of continuous positive airway pressure (CPAP) treatment for obstructive sleep apnea in arterial stiffness: a meta-analysis. Sleep Med Rev. 2013;17:19-28.

16. Levy P, Pepin JL, Arnaud C, Baguet JP, Dematteis M, Mach F. Obstructive sleep apnea and atherosclerosis. Prog Cardiovasc Dis. 2009;51:400-410.

17. Chung S, Yoon IY, Lee CH, Kim JW. The association of nocturnal hypoxemia with arterial stiffness and endothelial dysfunction in male patients with obstructive sleep apnea syndrome. Respiration. 2010;79: 363-369.

18. [No authors listed]. The Report of an American Academy of Sleep Medicine Task Force. Sleep-related breathing disorders in adults: recommendations for syndrome definition and measurement techniques in clinical research. Sleep. 1999;22:667-689.

19. Mancia G, Laurent S, Agabiti-Rosei E, et al. Reappraisal of European guidelines on hypertension management: a European Society of Hypertension Task Force document. J Hypertens. 2009;27: 2121-2158. 
20. Mancia G, De Backer G, Dominiczak A. 2007 Guidelines for the management of arterial hypertension. The Task Force for the Management of Arterial Hypertension of the European Society of Hypertension (ESH) and of the European Society of Cardiology (ESC). Eur Heart J. 2007;28:1462-1536.

21. Van Bortel LM, Laurent S, Boutouyrie P, et al; Artery Society; European Society of Hypertension Working Group on Vascular Structure and Function; European Network for Noninvasive Investigation of Large Arteries. Expert consensus document on the measurement of aortic stiffness in daily practice using carotid-femoral pulse wave velocity. J Hypertens. 2012;30:445-448.

22. Rogoza AN, Kuznetsov AA. Central aortic blood pressure and augmentation index: comparison between Vasotens ${ }^{\circledR}$ and SphygmoCor ${ }^{\circledR}$ technology. Research Reports in Clinical Cardiology. 2012;3:27-33.

23. Nagahama H, Soejima M, Uenomachi H, et al. Pulse wave velocity as an indicator of atherosclerosis in obstructive sleep apnea syndrome patients. Intern Med. 2004;43:184-188.

24. Doonan RJ, Scheffler P, Lalli M, et al. Increased arterial stiffness in obstructive sleep apnea: a systematic review. Hypertens Res. 2011;34: 23-32.

25. Parati G, Lombardi C, Hedner J, et al. Position paper on the management of patients with obstructive sleep apnea and hypertension: joint recommendations by the European Society of Hypertension, by the European Respiratory Society and by the members of European COST (COoperation in Scientific and Technological research) ACTION B26 on obstructive sleep apnea. J Hypertens. 2012;30:633-646.
26. Nichols WW, O'Rourke MF. McDonald's Blood Flow in Arteries: Theoretical, Experimental and Clinical Principles, 5th ed. London, UK: Hodder Arnold; 2005.

27. Kohler M, Craig S, Nicoll D, et al. Endothelial function and arterial stiffness in minimally symptomatic obstructive sleep apnea. Am J Respir Crit Care Med. 2008;178:984-988.

28. Williams B, Lacy PS, Thom SM, et al. Differential impact of blood pressure-lowering drugs on central aortic pressure and clinical outcomes: principal results of the CAFE study. Circulation. 2006;113 1213-1225.

29. Phillips CL, Yee B, Yang Q, et al. Effects of continuous positive airway pressure treatment and withdrawal in patients with obstructive sleep apnea on arterial stiffness and central BP. Chest. 2008;134:94-100.

30. Somers VK, Dyken ME, Clary MP, Abboud FM. Sympathetic neural mechanisms in obstructive sleep apnea. J Clin Invest. 1995;96: 1897-1904.

31. Shirai K, Utino J, Otsuka K, et al. A novel blood pressure-independent arterial wall stiffness parameter; cardio-ankle vascular index (CAVI), J.Atherosclerosis Thromb 2006 Apr;13(2):101-107.
Vascular Health and Risk Management

\section{Publish your work in this journal}

Vascular Health and Risk Management is an international, peerreviewed journal of therapeutics and risk management, focusing on concise rapid reporting of clinical studies on the processes involved in the maintenance of vascular health; the monitoring, prevention and treatment of vascular disease and its sequelae; and the involvement of

\section{Dovepress}

metabolic disorders, particularly diabetes. This journal is indexed on PubMed Central and MedLine. The manuscript management system is completely online and includes a very quick and fair peer-review system, which is all easy to use. Visit http://www.dovepress.com/ testimonials.php to read real quotes from published authors. 